\title{
Malignant Hypertensive Retinopathy Revealing Bilateral Renal Atrophy in Adolescent at Chu-Campus of Lomé
}

\author{
Kassoula Batomaguela Nonon-Saa, Abbevi Eli Abbey, Dadjo Amouzou*, Nidain Maneh, \\ Adam Nouhou Diori, Isreal Tchodjoou, Regine Mewamba Wamba, Kokou Vonor, \\ Kokou Messan Amedome, Koffi Didier Ayena, Komi Balo \\ Ophthalmology Department, University Hospital Center, Lomé, Togo
}

\section{Email address:}

nononsaap@yahoo.fr (K. B. Nonon-Saa), elieabbey90@gmail.com (A. E. Abbey), dadjooson@gmail.com (D. Amouzou), manehnid@hotmail.fr (N. Maneh), adamslalou@gmail.com (A. N. Diori), tchodjoouisrael@gmail.com (I. Tchodjoou), regwamba@gmail.com (R. M. Wamba), benvonor@gmail.com (K. Vonor), amedomekokoumessan@gmail.com (K. M. Amedome), didierayena@gmail.com (K. D. Ayena), komibalo@yahoo.fr (K. Balo)

${ }^{*}$ Corresponding author

\section{To cite this article:}

Kassoula Batomaguela Nonon-Saa, Abbevi Eli Abbey, Dadjo Amouzou, Nidain Maneh, Adam Nouhou Diori, Isreal Tchodjoou, Regine Mewamba Wamba, Kokou Vonor, Kokou Messan Amedome, Koffi Didier Ayena, Komi Balo. Malignant Hypertensive Retinopathy Revealing Bilateral Renal Atrophy in Adolescent at Chu-Campus of Lomé. International Journal of Ophthalmology \& Visual Science. Vol. 4, No. 3, 2019, pp. 42-45. doi: 10.11648/j.ijovs.20190403.11

Received: June 10, 2019; Accepted: July 23, 2019; Published: August 8, 2019

\begin{abstract}
Malignant hypertension, which was defined as the association of a severe elevation of blood pressure with retinopathy stage III or IV according to KEITH and WAGENER, now takes into account the involvement of the noble organs such as central nervous system, heart and kidneys. It is this attack that determines the severity, urgency and vital prognosis of this pathology. Uncommon in children and teenagers, malignant hypertension often secondary, involving kidney in the most cases. It is a therapeutic emergency because it is at risk to progress into hypertensive encephalopathy, stroke, acute renal failure, or heart failure, all of which represent its usual pattern of discovery. We report the case of malignant hypertension in a teenager without personal pass history of hypertension. The singularity of this report case is the uncommon mode of his discovery: isolated bilateral visual impairment. This clinical case challenges us and reminds the interest of the funduscopic examination during ophthalmological consultation, and teaches us that taking the blood pressure of a teenager who consults for an isolated bilateral decrease of vision is not without interest. Early recognition and management of malignant hypertension, are fundamental to any improvement in prognosis of this serious disease.
\end{abstract}

Keywords: Malignant Hypertension, Neurorerinitis, Renal Atrophy

\section{Introduction}

Malignant hypertension is defined by the association of severely elevated blood pressure (blood pressure above 180 $\mathrm{mm} \mathrm{Hg} / 120 \mathrm{~mm} \mathrm{Hg}$ ) with a Keith and Wagener stage III or IV retinopathy. It may occur in a person with known or unknown hypertension, treated or untreated [1-3]. Nevertheless, this definition should be reconsidered as Cremer et al. [4]; rightly point out in their study. In fact, this definition does not take into account the damage caused by the severe elevation of blood pressure on the target organs, which are the central nervous system, the heart and the kidneys. It is this attack that determines the severity, urgency and vital prognosis of this pathology [4]. It is an uncommon disease in adults and even scarce in children or adolescents [5-7]. Because the risk to progress into hypertensive encephalopathy, stroke, progressive renal failure, or heart failure, all of which represent its usual pattern of discovery; it is a therapeutic emergency $[4,8,9]$.

We report the case of a malignant hypertension in a teenager without personal pass history of hypertension, and who has an uncommon mode of discovery: a bilateral and isolated decline of visual acuity.

\section{Observation}


It was a 19-years-olds dressmaker's apprentice brought at the Ophthalmology Department of the CHU-Campus (University Hospital Center of Lomé) by her guardian for a bilateral visual acuity decrease occurred a week ago with quickly progressive installation. She would have presented the days before, difficulties to threading a thread into a needle at work. This incident would have alerted her boss. Add to that, she complained of headaches treated in selfmedication as malaria with remission.

The impairment of visual acuity which became a handicap had motivated an ophthalmological consultation. The patient had no particular personal history but her family history make out the fact that her younger brother died at the age of 15 in a context of edematous-ascitic syndrome.

At examination the right eye's visual acuity was $1 / 10$ and Parinaud 15 not improving on the correction attempt. The anterior segment was normal. The lens was clear. Fundoscopy noted papilloedema with generalized narrowing of arteriolar diameter, focal point of flame haemorrhages, cotton-wool spots, hard exudates in the entire field, but mostly concentrated at the level of the macula giving the macular star aspect neuroretinitis (Figure 1).

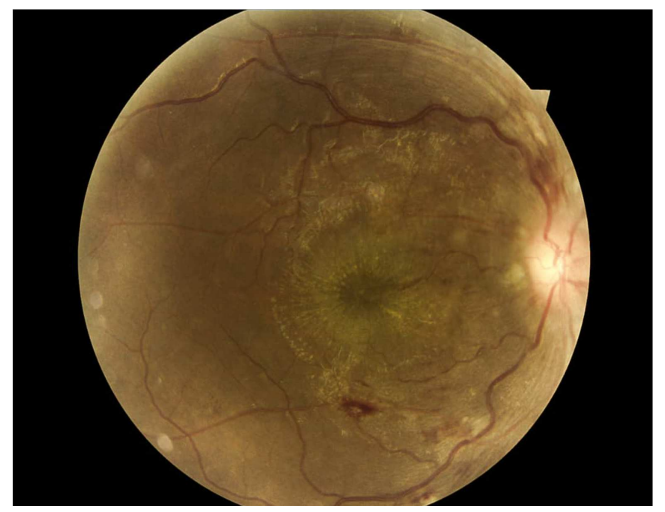

Figure 1. Right eye retinography.

The left eye visual acuity was limited to "count fingers at 2 m", Parinaud 15 not improve after correction test. The anterior segment and vitreous were normal. On examination of fundus, the signs were superimposed on those observed on the right eye (Figure 2).

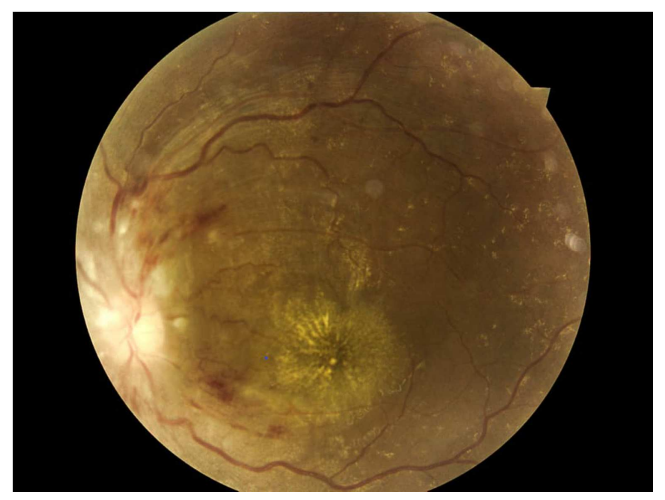

Figure 2. Left eye retinography.

In an etiological approach, it was decided the measurement of the blood pressure which noted: $210 \mathrm{~mm} \mathrm{Hg} / 130 \mathrm{~mm} \mathrm{Hg}$. In front of this blood pressure we conclude to a stage IV of hypertensive retinopathy according to Keith and Wagener classification. The patient was sent immediately to the Cardiological Emergencies. The blood test results were: uremia at $17.9 \mathrm{~g} / \mathrm{l}$ or 40 times the normal rate; serum creatinine at $97 \mathrm{mg} / \mathrm{l}$, which is 7 times the normal level, with clearance of creatinine at $6.69 \mathrm{ml} / \mathrm{min}$, normal at $87-107$ $\mathrm{ml} / \mathrm{min}$; severe anaemia at $7.2 \mathrm{~g} / \mathrm{dl}$, disturbed phosphocalcic balance with hypocalcaemia at $70 \mathrm{mg} / \mathrm{l}$, and hypoproteinemia.

According to these biological results, the diagnosis of severe chronic renal failure probably due to undetected glomerular nephropathy was discussed. Kidney ultrasonography showed small kidneys moderately dedifferentiated at Stage II: right kidney $=68 \times 36 \times 24$ $(\mathrm{mm})$; Left kidney $=68 \times 36 \times 24(\mathrm{~mm})$ giving a bilateral renal atrophy (Figure 3).
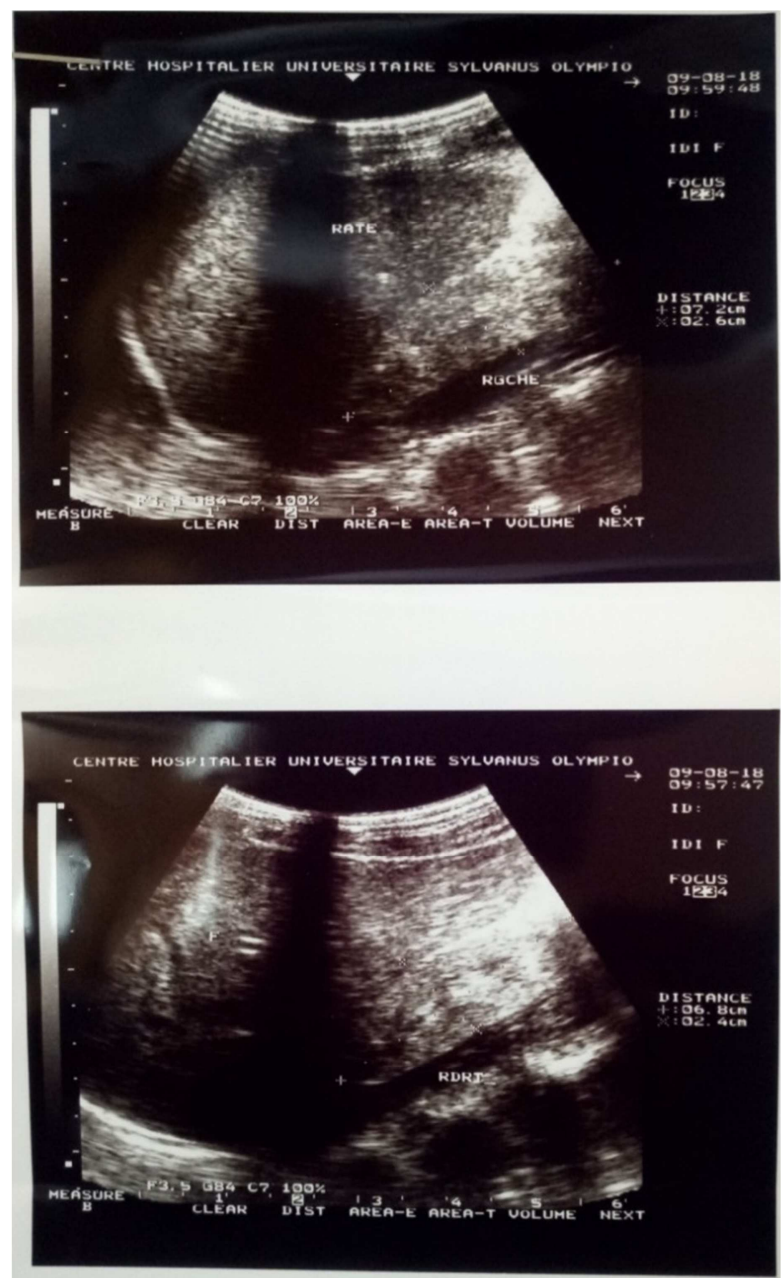

Figure 3. Renal ultrasound.

In summary, we conclude to malignant hypertension secondary to chronic renal failure with bilateral renal atrophy.

In front of these cardio-nephrological advanced signs that are life-threatening to the patient, hypertension and renal failure treatment were first to ophthalmic one. 


\section{Discussions}

\subsection{At the Clinical Level}

The fast progressive bilateral visual acuity impairment motivated the consultation, which allowed us to discover the ophthalmoscopic signs of bilateral neuroretinitis. It was necessary to find the etiology of this one and before undertaking the biological, infectious and other explorations; we took blood pressure and noted $210 / 130 \mathrm{~mm} \mathrm{Hg}$ at rest in both arms. This has led to the retention of severe hypertensive retinopathy in the context of malignant hypertension, which is usually diagnosed following a complication like hypertensive encephalopathy, stroke, progressive renal failure, cardiac failure [8]. In adolescents, malignant hypertension can occur in different presentations. Some patients will have severe clinical presentations such as heart failure or stroke, while others will be completely asymptomatic for several months [4].

Ophthalmologic manifestations as an isolated sign of discovery of this pathology are rare, which makes the singularity of our clinical case [6, 10]. Lam et al. [11] described a case of malignant hypertension in a 7-year-old girl with pheochromocytoma in the context of Von HippelLindau syndrome. The young patient had isolated bilateral visual acuity impairment, with bilateral papilloedema and macular star at funduscopic examination. Blood pressure, which was normal at the beginning $(110 / 70 \mathrm{~mm} \mathrm{Hg})$, had risen within a few days to $224 / 160 \mathrm{mmHg}$ allowing to retain the diagnosis of a malignant hypertension which one had to look for the cause. They recommended at the time the systematic and repeated taking of the blood pressure whatever the age, in case of neuroretinitis, recommendation that our clinical case consolidated [12]. In addition to that, Maweni et al. [13] in their cohort study in a British hospital about 63 black patients, make the same recommendation.

\subsection{Etiologically}

The investigation of the etiology of malignant hypertension found chronic renal failure with bilateral renal atrophy. It must be said that renal causes are the first etiology of malignant hypertension in young patients: acute hypertensive glomerulonephritis is described, chronic glomerulonephritis, acute or chronic renal failure and reno-vascular causes $[1,5$, 14]. In United statses of America Webb et al. [15] in their study concerning children and adolescents hospitalized for severe hypertensive crisis, note that unlike adults, malignant hypertension is most often secondary to other chronic diseases. Non-renal causes are rarer. Nonetheless, pheochromocytomas: tumors developed at the expense of chromaffin cells of the sympathetic nervous system that secrete a combination of dopamine, nor-epinephrine and adrenaline [8]. Unlike adults with chronic kidney disease, which is considered like consequence of hypertension, in adolescents the renoparenchymal or reno-vascular pathology makes the bed at hypertension in at least $85 \%$ of cases. The prevalence of hypertension secondary to chronic kidney disease in children and teenagers is between 20 and $80 \%$ depending on the degree of renal dysfunction [16].

In our patient, the hypertension is malignant and probably due to renal disease which led to renal atrophy then chronic renal failure, thus we are reinforcing data from the literature concerning the link between reno-vascular diseases and the occurrence of malignant hypertension in children and adolescents $[14,16]$.

\section{Conclusion}

Malignant hypertension is often related to renal causes in children and adolescents. It remains diagnostic and therapeutic emergency. This clinical case challenges us and reminds the interest of the funduscopic examination during ophthalmological consultation. He teaches us that taking blood pressure in a teenager who is seen for an isolated bilateral visual acuity decrease is not a superfluous act, let alone if the patient's fundoscopy reveals a neuroretinitis. This simple motion will help to avoid missing out a malignant hypertension evolving insidiously, but with serious consequences. Early recognition and management of malignant hypertension, are fundamental to any improvement in prognosis of this pathology.

\section{Conflict of Interest}

The authors declare that they have no competing interests.

\section{Contributions of the Authors}

All cited authors participated in the writing and / or the correction of this manuscript of which they have approved the final version.

\section{References}

[1] The sixth report of the Joint National Committee on prevention, detection, evaluation, and treatment of high blood pressure. Arch Intern Med. 24 nov 1997; 157 (21): 2413-46.

[2] Gifford RW. Management of hypertensive crisis. Jama. 1991 Aug 14; 266 (6): 829-35.

[3] Keith NM, Wagener HP, Barker NW. SOME DIFFERENT TYPES OF ESSENTIAL HYPERTENSION: THEIR COURSE AND PROGNOSIS: Am J Med Sci. 1974 dec; 268 (6): 336-45.

[4] Cremer A, Amraoui F, Lip GYH, Morales E, Rubin S, Segura $\mathrm{J}$, et al. From malignant hypertension to hypertension-MOD: a modern definition for an old but still dangerous emergency. $\mathrm{J}$ Hum Hypertens. 2016 Aug; 30 (8): 463-6.

[5] Leitão A, Fernandes S, Guimarães Dinis J, Melo e Sousa A, Sousa A. [Hypertensive crisis in adolescence... what is it?]. Acta Med Port. déc 2011; 24 Suppl 3: 653-6.

[6] Joseph T. Flynn \& Kjell Tullus. Severe hypertension in children and adolescents: Pathophysiology and treatment Pediatr Nephrol. 2009; 24: 1101-1112. 
[7] Seeman T, Hamdani G, Mitsnefes M. Hypertensive crisis in children and adolescents. Pediatr Nephrol Berl Ger. 2018 oct 1 .

[8] El haddad S, Benchekroun N, Rhafour A, Ahbeddou S, Rhafour I, Imdary I, et al. Bilateral stellate neuroretinitis as presenting sign of pheochromocytoma. J Fr Ophtalmol. 2013 sep; 36 (7): 600-3.

[9] Gonzalez R, Morales E, Segura J, Ruilope LM, Praga M. Long-term renal survival in malignant hypertension. Nephrol Dial Transplant 2010; 25: 3266-3272.

[10] Bender SR, Fong MW, Heitz S, Bisognano JD. Characteristics and Management of Patients Presenting to the Emergency Department With Hypertensive Urgency. J Clin Hypertens. 2006 Jan; 8 (1): 12-8.

[11] Lam B, Shah V, Zlotcavitch L, Herro A, Dubovy S, Yehoshua Z. Bilateral papillopathy as a presenting sign of pheochromocytoma associated with von Hippel\&ndash; Lindau disease. Clin Ophthalmol. 2014 Mar; 623.
[12] Belsha CW. Pediatric Hypertension in the Emergency Department. Ann Emerg Med. 2008 Mar; 51 (3): S21-3.

[13] Maweni RM, Sunderland N, Rahim Z, Odih E, Kallampallil J, Saunders $T$, et al. Clinical characteristics of Black patients with hypertensive urgency. Ir J Med Sci $1971-2018$ nov; 187 (4): 1089-96.

[14] Kota SK, Kota SK, Meher LK, Sruti J, Kotni G, Panda S, et al. Clinical analysis of hypertension in children: an urban Indian study. Saudi J Kidney Dis Transplant off Publ Saudi Cent Organ Transplant Saudi Arab. 2013 Jul; 24 (4): 844-52.

[15] Webb TN, Shatat IF, Miyashita Y. Therapy of Acute Hypertension in Hospitalized Children and Adolescents. Curr Hypertens Rep [Internet]. 2014 avr [cité 8 Jul 2019]; 16 (4).

[16] Lurbe E, Agabiti-Rosei E, Cruickshank JK, Dominiczak A, Erdine S, Hirth A, et al. 2016 European Society of Hypertension guidelines for the management of high blood pressure in children and adolescents. J Hypertens. 2016; 34 (10): 1887-920. 